\title{
The Application of Teaching of Intelligent Mobile Equipment in Plant Pathology in the Case of Hebei North University
}

\author{
Fengying Shen ${ }^{1,2}$, Weigang Wu ${ }^{1}$, Junhai Yuan ${ }^{1}$, Lijie Qu ${ }^{1}$, Huijing Guo ${ }^{1}$, Dong Wei ${ }^{1,2, ~}$, \\ Yinghui Liu, * \\ ${ }^{1}$ Agricultural and Forestry Science and Technology College of Hebei North University, Zhangiakou, China \\ ${ }^{2}$ Hebei Key Laboratory of Quality \& Safety Analysis-Testing for Agro-Products and Food, Hebei North University, Zhangjiakou, China
}

Email address:

Zhibao200221@163.com (Fengying Shen), weigang99@163.com (Weigang Wu),hbzjkwd@163.com (Dong Wei), leely519@126.com (Yinghui Liu)

*Corresponding author

\section{To cite this article:}

Fengying Shen, Weigang Wu, Junhai Yuan, Lijie Qu, Huijing Guo, Dong Wei, Yinghui Liu. The Application of Teaching of Intelligent Mobile Equipment in Plant Pathology in the Case of Hebei North University. Teacher Education and Curriculum Studies.

Vol. 5, No. 3, 2020, pp. 61-65. doi: 10.11648/j.tecs.20200503.13

Received: November 25, 2019; Accepted: June 20, 2020; Published: June 28, 2020

\begin{abstract}
Because of prices dropping of the intelligent mobile equipment, popularization rate is improved, and provide a solid hardware foundation for its assisted instruction. The novel coronavirus outbreak in 2019, students can not learn new knowledge in school, teachers and students with intelligent mobile devices through the network teaching and learning new knowledge. Plant pathology is one of the important professional basal courses of plant protection. The intelligent mobile equipment play an important role in the theory teaching, practice teaching, teaching management of plant pathology. So the article points out that in order to meet the teaching need we should give full play to the function of the digital devices. Hebei North University is located in Zhangjiakou City, Hebei Province. It is a comprehensive undergraduate college that covers 10 disciplines including agronomy. The phytopathology-related course is an important professional basic course for the undergraduate students. It mainly teaches the causes of plant diseases, the occurrence and development of diseases, the interaction between plants and pathogens, and the principles and methods of plant disease prevention. During the epidemic period, intelligent mobile device network teaching has provided great convenience for the teaching of plant pathology in plant protection specialty, which enables us to complete the necessary teaching tasks at home, and students can communicate with teachers in time.
\end{abstract}

Keywords: Digital Equipment, Intelligent Mobile Equipment, Plant Pathology, Teaching Practice

\section{Teaching Status of Plant Pathology in Hebei North University}

Hebei North University has 6 undergraduate majors and 6 specialties majors in plant pathology related courses. The majors are distributed in two secondary colleges, the Agriculture and Forestry Science and Technology College and the Animal Science and Technology College. There are differences in the different training programs (see Table 1). At present, most of the school's plant pathology courses use multimedia-assisted teaching methods. The theoretical teaching adopts teaching methods based on lectures and teachers and students' questions and answers. There is no necessary interaction between teachers and students. The experimental course recognizes plant pathogenic microorganisms by means of wall charts, slide shows, or by observing purchased microscope sections. Teacher-student exchanges are limited to limited class time and lack the necessary communication after class.

Table 1. Course setting of plant pathology in Hebei North University.

\begin{tabular}{|c|c|c|c|c|c|c|}
\hline Profession & Name & Level & Total hours & Theory & Experiment & Semester \\
\hline Plant protection & Agricultural plant pathology & Bachelor & 108 & 84 & 24 & $6 / 7$ \\
\hline Seed Science and Engineering, Agriculture & Agricultural plant pathology & Bachelor & 72 & 52 & 20 & 6 \\
\hline
\end{tabular}




\begin{tabular}{|c|c|c|c|c|c|c|}
\hline Profession & Name & Level & Total hours & Theory & Experiment & Semester \\
\hline Plant Science and Technology & Plant pathology & Bachelor & 54 & 38 & 16 & 7 \\
\hline Plant protection & Common plant pathology & Bachelor & 72 & 52 & 20 & 5 \\
\hline Gardening & Horticultural plant pathology & Bachelor & 72 & 52 & 20 & 5 \\
\hline Animal and plant quarantine & Plant pathology & Bachelor & 36 & 26 & 10 & 2 \\
\hline Plant protection & Common plant pathology & Specialist & 72 & 52 & 20 & 5 \\
\hline Plant protection & Agricultural plant pathology & Specialist & 90 & 64 & 26 & $6 / 7$ \\
\hline $\begin{array}{l}\text { Crop production technology, seed production } \\
\text { and management }\end{array}$ & Agricultural plant pathology & Specialist & 90 & 52 & 38 & 4 \\
\hline $\begin{array}{l}\text { Gardening technology (fruit and vegetable } \\
\text { direction, vegetable direction) }\end{array}$ & Fruit tree pathology & Specialist & 72 & 48 & 24 & 4 \\
\hline Garden technology & Garden plant pathology & Specialist & 72 & 48 & 24 & 5 \\
\hline
\end{tabular}

\section{Application Status of Intelligent Mobile Devices in Teachers and Students}

Advances in technology have made the cost of smart digital devices lower and lower, and the popularity has also increased. The smart digital devices used in teaching practice mainly include smart phones and tablet computers.

Smart phone refers to a separate operating system suitable for mobile phone operation, such as a personal computer. The user installs a software program provided by a third-party service provider to expand the functions of the mobile phone and has powerful multimedia audio-visual functions. A general term for a class of mobile phones with unlimited internet communication capabilities.

Because the mobile phone has a broad audience base and a wide range of information, it is called the "fifth media". That is, through the mobile terminal represented by the mobile phone, the media form of the information content is presented. In addition to its fast processing speed, high screen resolution, large storage capacity and powerful multimedia functions, smartphones also have an open operating system and support powerful network and data application functions. For college students, they have a unique appeal and users are increasing. In 2010, China Telecom promoted the wing machine business in Hebei North University, and equipped each student of our school with China Telecom's 3G smart phone. The service fee is relatively low, which objectively promotes the popularization and application of smart phones in campus life.

Tablet Personal Computer, proposed by Bill Gates, is a small, portable personal computer that uses a touch screen or stylus instead of a traditional keyboard and mouse as a basic input device.

In 2010, the Apple iPad set off a tablet PC boom around the world. A number of analysts have indicated that global tablet sales will increase significantly in 2013, totaling more than 200 million units. Gartner predicts that global shipments of tablet PCs will surge by $67.9 \%$ to 202 million units in 2013; IDC expects tablet shipments to reach 229 million units this year, up $58.7 \%$ from last year, and global tablet sales in the next few years. It will continue to rise and will exceed 400 million units in 2017. Display Search's report shows that global tablet sales will increase by $64 \%$ in 2013 to 240 million units. Driven by small local brands, the sales of domestically produced tablet PCs in China will reach 65 million units in 2013 , with a market share of $27 \%$. In terms of teaching, the teaching of the Beijing Zhong guan cun No. 1 Primary School and the Open Class of the First Middle School of Huanggang City, Hubei Province was all carried out through a tablet computer $[4,5]$.

Teachers and students in colleges and universities, as a special group, are active in thinking and have a new and fast demand for information, enabling them to quickly accept new technologies and promote the popularization and application of new technologies. Most of the contemporary college students are 90s. They are a new generation that keeps up with the trend of the times. They have a strong sense of pursuit for smartphones and tablets with the latest technology, so mobile information projects are easily accepted.

\section{Application Survey and Analysis of Teaching Practice Based on Intelligent Mobile Devices}

Taking the 2011 students of Hebei North University of Agriculture and Forestry Science and Technology as a sample, 200 questionnaires were randomly distributed and 192 valid questionnaires were collected. According to the survey, 188 students have smartphones, accounting for $96 \%$, that is, 20 students have tablets, accounting for $10.41 \%$, which indicates that smart mobile devices have a material basis for teaching practice. In terms of the demand for learning for smart mobile devices, $2.60 \%$ are often used, $75.52 \%$ are occasionally used, and $21.88 \%$ are never used. In addition, $98.96 \%$ of college students who already have a smartphone said they have a need to use mobile phone learning courses. The survey shows that most college students are not satisfied with their time and place of study, and more college students hope to study at any time and anywhere they want to study. Smartphones are easy to carry and also enable students to access resources online anytime, anywhere. For college students, this kind of learning method based on digital learning effectively combined with mobile computing technology not only makes up for the limited defects of classroom teaching resources, but also cultivates the independent learning ability of college students [6]. 


\section{Application of Intelligent Mobile Equipment in Plant Pathology Teaching}

\subsection{Using Mobile Phone QQ Multimedia Function to Assist Teaching}

First, the establishment of the QQ group of plant pathology teaching, can enable the teachers and students to join independently, can have a good interaction after class, and become an open platform for discussion and answering questions. Give full play to the multimedia function of QQ space, and establish modules such as "teaching documents", "experiments", "exercises", "plant disease picture database", "plant pathology data download area" and "problem discussion" in QQ space. Secondly, organize students to use the QQ multimedia function module of the smartphone or tablet to learn the experience under the class, make full use of the camera and camera functions, and upload photos or videos of plant pests and diseases encountered to the problem discussion area anytime and anywhere. The teacher conducted disease identification and finally selected a typical photo uploaded to the "plant disease picture database" in the QQ space for students to check. Third, improve and improve the QQ multimedia teaching function, and organically combine with traditional teaching to foster strengths and avoid weaknesses and improve teaching quality. Fourth, the teaching of plant pathology does not end with the end of the semester teaching activities. During the summer and winter vacations, make full use of QQ multimedia functions for tracking teaching and instant voice teaching as well as video demonstration teaching. In the process of cultivating students' follow-up professional ability, students may encounter certain plant diseases in practice, and they can consult professional teachers through QQ.

\subsection{Make Full Use of the Bluetooth Function of the Smartphone}

At present, the popularity of the network brings great convenience to people's learning and life, and its greatest advantage is resource sharing. The wireless communication function of GPRS, WIFI and Bluetooth is configured in the smart phone system. Through the application of these functions, the bits and pieces of student records can be transmitted, discussed and learned from each other, and these resources are organized to form a knowledge network [7-9].

\subsection{Open the Teaching of Plant Pathology Blog, Weibo}

Open the Plant Pathology Teaching Blog, which can share teaching materials such as teaching documents, lesson plans, teaching plans, and exercises, so that students can download and learn. A discussion of the issue can be initiated on the blog. Each student can express their own opinions, and the teacher should also participate in the discussion to guide the students to pioneering learning [10-14].

Open the micro-blog of plant pathology teaching, and pass the main content of the preparation course to the students before the formal teaching, so that the students are prepared to have lectures to listen to. Through the microblog interactive platform, the number of words in the course preview content is limited to 140 words, and the content, key points and difficulties of the 2 hours of each lesson are summarized into five below microblogs, which are released one day in advance. Make students have a purpose to prepare the course content before the official class, and take the questions to attend classes [15-18]. After class, the knowledge points, after-school thinking questions or problem discussions involved in this section will be published on Weibo, so that students can review and correct the knowledge under the class, so that the professional knowledge can be consolidated and improved [19-21].

\subsection{Using the Existing Blackboard Teaching Management Platform to Open a Network Course on Plant Pathology}

Blackboard Learning SystemTM, referred to as the BB network-assisted teaching platform, is widely recognized as the industry's leading course-led management system. The teaching platform provides a new way for the teaching practice of higher education. The use of the platform is centered on the curriculum, and the environment of "teaching" and "learning" is distributed on the network [22]. Teachers can open online courses on the platform. release teaching instructions, upload teaching courseware, etc., learners can choose the course to be studied and learn the course content. In the process of learning, we pay attention to the exchanges and discussions between teachers and students, and between students, which forms a good learning atmosphere and makes up for the lack of traditional classroom teaching and answering questions [23].

Hebei North University purchased the right to use the BB network-assisted teaching platform and Learning Software which made by superstar company, but in the process of teaching practice, the utilization rate is not high, and the teachers and students are not paying enough attention. This is bound to cause a lot of waste and does not play the role of the platform. Therefore, the training of the teaching platform will continue to be strengthened, so that teachers can use it well, so as to fundamentally improve the teaching level.

At the same time, Bluetooth can only achieve peer-to-peer transmission, that is, a student can only send data to a student, and it is time-consuming and laborious to pass a valuable data to a full-time student. In view of this shortcoming, make full use of the existing right to use the BB network-assisted teaching platform purchased by our school, so that after the students upload the materials, they can be downloaded to all the students through the review of the teachers.

\section{Conclusion}

In summary, When novel coronavirus epidemic was launched in the spring semester of 2020, students stopped classes and universities were mainly taught through network teaching, such as learning, Tencent meetings, rain classes, etc., 
and teachers constantly explored the network teaching mode in the process of online teaching, "No suspension of classes" is an important opportunity to promote "classroom revolution", showing the characteristics of flexible teaching, independent learning, on-demand selection, respect for differences, open resources, scientific and technological support, government leadership, school organization, home school linkage, social participation, etc. the key to organizing a large-scale Internet Education is to organize and implement "smooth communication platform, appropriate digital resources Seven key elements are convenient learning tools, diverse learning methods, flexible teaching organization, effective support services and close coordination between government, enterprise and school [20-23].

Higher education teaching can't be limited to traditional teacher classroom teaching. In today's fast-changing technology and mobile Internet technology, the application of smart mobile devices, such as tablets and smart phones, in higher education teaching has never been Yes, more and more widely. The growing number of students with intelligent terminal equipment provides a hardware foundation for the application of intelligent mobile devices in the teaching of plant pathology. On this basis, as a implementer of higher education, the teacher should make full use of this convenience. To enable students to make full use of limited hours and gain knowledge and improve their abilities through new ways. Of course, we should also be soberly aware that traditional classroom teaching should not be replaced and weakened. Intelligent mobile devices can only serve as an effective auxiliary form for students to learn.

\section{Acknowledgements}

The authors acknowledge the Foundation: National Agricultural Education Index Committee (2019-NYYB-15); Hebei North University 2019 school level teaching reform project "Application of flipped classroom based on micro course in biological control technology course" (GJ2019022); Ministry of education, Ministry of agriculture and State Forestry Administration: pilot project for the reform of excellent agricultural and forestry talents education and training plan.

\section{References}

[1] SHEN Feng-ying, WU Wei-gang, WU Cheng-wei, et al. Application of Intelligent Mobile Equipment in Plant Pathology Teaching [J]. 2015.

[2] Yin L, Wang W. The Application of Facial Characteristics Extraction in the Intelligent Network Teaching System [C]// 2009.

[3] Peng Y. Application and analysis of intelligent exam system in theory teaching of Chinese sports colleges and universities $[\mathrm{C}] / / 2011$.

[4] Fan L, Dai F, Cui S, et al. Internet of Things Experimental Equipment Innovation: A New Internet of Things Teaching
Instrument Based on Android Mobile Phones [M]// Computer Science and Engineering Technology (CSET2015) \& Medical Science and Biological Engineering (MSBE2015): Proceedings of the 2015 International Conference on CSET \& MSBE.

[5] Liu Shukun, Yang Xiaohua. The Application of Bilingual Teaching of Operating System in Private College [C]// Intelligent Computing and Cognitive Informatics (ICICCI), 2010 International Conference on. 2010.

[6] Zhong S. Application of Intelligent Mobile Phones in College English Teaching [J]. Journal of Changchun University, 2017.

[7] LU Yiming, GUO Shanshan, QIU Lei, et al. Application of PBL teaching model based on online platforms in the teaching of biotechnological drugs. Basic Medical Education, Feb. 2019, Vol. 21 No. 2.

[8] Xiao Meiyan, Lai Yongjie, Yu Yan. Application of superstar network teaching platform in Microbiology Teaching Reform $[\mathrm{J}]$. Food and fermentation technology, 2020, 56 (01): $120-123$.

[9] Jia Rongwu. On the reform of English teaching mode in Higher Vocational Education under the network multimedia environment $[\mathrm{J}]$. Chinese Journal of multimedia and network teaching, 2020 (02): 10-11.

[10] Shen pingqiang. Interactive teaching of information technology supported by semi open source network platform $[\mathrm{J}]$. Digital teaching in primary and secondary schools, 2020 (02): 43-45.

[11] Liu liangbo, Jiang song, sun Yanming. Practice and exploration of veterinary foreign science curriculum reform under the background of information age [J]. Heilongjiang Animal Husbandry and veterinary, 2020 (03): 140-145.

[12] Wang Na, Zhang Yinghui. The construction of online courses in higher education institutions under the background of "Internet plus" -- Taking Northwest Agriculture and Forestry University as an example [J]. China forestry education, 2020, 38 (01): 18-20.

[13] Asida. Teaching reform of computer network principle course based on network simulation software [J]. Computer education, 2020 (01): 37-41.

[14] Li Zhengzheng. Implementation method of course construction based on superstar learning network platform -taking financial management as an example [J]. Think tank era, 2020 (01): 182-183.

[15] Lin Jingna. Research on practical teaching reform of network engineering [J]. Office automation, 2020, 25 (01): 32-33.

[16] Li Hongbo, Li Na, Zhou Wei, Zhang Hao, Hu Liangbin, Mo Haizhen. Discussion on interest teaching reform of food biochemistry in the era of mobile Internet [J]. Light industry technology, 2020, 36 (01): 180-182.

[17] Zhao Qiuyan, Huang Xianqing, Qiao Mingwu, Cui Wenming, Zhang Qiuhui, Wang Fan, song Lianjun. Exploration and practice of "food analysis and inspection" experimental teaching mode under modern information network $[\mathrm{J}]$. Agricultural products processing, 2019 (24): 108-111.

[18] Cai Li. Research on Ideological and political education reform of computer network course [J]. Education modernization, 2019, 6 (A4): $96-97+100$. 
[19] Xia Junli, Ren Huijing, Tang Wenwen, Yang Ying, Luo Liya. The reform of Biochemistry Teaching in Higher Vocational Education [J]. Henan agriculture, 2019 (36): 42-43.

[20] Yuan Lianyu, Wu Zhijun, Tong Huarong, Meng Qing, Zeng Liang. Problems and reform measures in the teaching of tea tree genetics and breeding [J]. Journal of Southwest Normal University (NATURAL SCIENCE EDITION), 2019, 44 (12): 137-140.

[21] Dong He. On the application path of network teaching resources in biology classroom teaching [J]. Chemical management, 2019 (35): 18-19.
[22] Zhang Bo, Jia Zhongtian, Liu Yue, Jing Shan. Discussion on the teaching reform of network security protocol course $[\mathrm{J}]$. Computer education, 2019 (12): 43-45.

[23] Cui Zhifang, Li Huijuan. Teaching reform and practice exploration of biochemistry in engineering colleges [J]. Education modernization, 2019, 6 (94): 81-82 + 100 .

[24] Ma Guang. The importance of e-learning in bioinformatics Teaching Reform $[\mathrm{J}]$. Modern rural science and technology, 2019 (08): 67-68. 